Cahiers $d u$ MONDE RUSSE

\section{Cahiers du monde russe}

Russie - Empire russe - Union soviétique et États indépendants

$50 / 4 \mid 2009$

Varia

\title{
Tricia Starks, The Body Soviet
}

\section{Grégory Dufaud}

\section{OpenEdition \\ Journals}

Édition électronique

URL : https://journals.openedition.org/monderusse/7167

DOI : $10.4000 /$ monderusse. 7167

ISSN : $1777-5388$

\section{Éditeur}

Éditions de l'EHESS

Édition imprimée

Date de publication : 15 décembre 2009

Pagination : 810-812

ISBN : 978-2-7132-2261-0

ISSN : $1252-6576$

\section{Référence électronique}

Grégory Dufaud, «Tricia Starks, The Body Soviet », Cahiers du monde russe [En ligne], 50/4 | 2009, mis en ligne le 12 janvier 2011, consulté le 03 septembre 2022. URL : http://journals.openedition.org/ monderusse/7167 ; DOI : https://doi.org/10.4000/monderusse.7167

Ce document a été généré automatiquement le 3 septembre 2022.

Tous droits réservés 


\title{
Tricia Starks, The Body Soviet
}

\author{
Grégory Dufaud
}

\section{RÉFÉRENCE}

Tricia STARKS, The Body Soviet. Propaganda, Hygiene and the Revolutionary State.

Madison : The University of Wisconsin Press, 2008, 313 p.

1 Pour les bolcheviks, la révolution devait apporter ordre et salubrité à une Russie crasseuse et obscurantiste. La pureté, qui devait incarner la rupture entre l'ancien et le nouveau, était un idéal politique, social et sanitaire: l'enjeu de santé publique s'accompagnait du souci d'épurer la société de ses éléments bourgeois et capitalistes. Le corps biologique, voulu sain et propre, était aussi une métaphore de la communauté née d'Octobre, susceptible d'être excisée pour en extirper les parties malades ou malsaines.

2 À partir de ce constat, Tricia Starks entreprend de raconter l'histoire du corps soviétique dans les années 1920, plus exactement la façon dont la propagande a véhiculé les thèses hygiénistes du nouvel État. Affirmant qu'il est difficile de connaître la portée réelle des mesures du commissariat à la Santé (Narkomzdrav), l'auteur circonscrit son étude au discours et aux représentations, proposant une "enquête culturelle des idéologies forgées, transformées et transmises par les organisations de la Santé et les activistes révolutionnaires, qui se déployèrent dans les différentes parties de l'Union soviétique » (p. 8). Le propos est centré sur Moscou qui, devenue capitale de la RSFSR en 1918, a bénéficié de l'attention toute particulière des autorités qui désiraient en faire un modèle pour l'ensemble du pays. Les sources exploitées sont nombreuses et variées: affiches, imprimés, documents issus pour l'essentiel du GARF (Archives d'État de la Fédération de Russie) et des centres d'archives de la ville et de la région de Moscou.

3 L'ouvrage est composé de six chapitres thématiques. Il commence par souligner les préoccupations des bolcheviks pour l'hygiène, qui s'inscrivaient dans l'exaltation des idéaux communautaires, de la médecine et de la science. Celles-ci entendaient assainir le corps et l'esprit en intervenant dans tous les aspects de la vie afin de faire advenir la société nouvelle qui, débarrassée des vestiges du capitalisme, ne compterait que des 
individus en bonne santé et à l'abri des épidémies. D'un point de vue politique, la première décennie du régime, avec l'instauration de la NEP qui maintenait une forme d'économie de marché, fut toutefois une période de coexistence du "propre » et du « sale ». La purification des individus en fut rendue d'autant plus impérieuse. L'hygiène fut alors considérée comme l'un des moyens de transformer ces derniers en les faisant accéder à une part de cet avenir qui leur avait été promis.

Sous la tutelle de Nikolaj Semačko, le Narkomzdrav lança un vaste programme destiné à prendre en charge la santé des Soviétiques. Le deuxième chapitre détaille la série d'institutions qui furent développées : hôpitaux et sanatoriums, destinés aux malades ; consultations et dispensaires, dont certains spécialisés, ayant essentiellement pour mission la prévention. La nécessité de surveiller l'état de santé de la population soviétique suscita la production de statistiques qui permirent de dresser un bilan. Parallèlement aux établissements, mis en place avant la révolution, le commissariat à la Santé créa des «maisons de repos» (dom otdyha). Cette structure médicalisée alliant repos et loisirs était inédite, ce que la propagande ne manqua pas de souligner. Elle fut d'autant plus utilisée que le Narkomzdrav, dont le budget fut rapidement amputé, ne parvint jamais à atteindre les objectifs qu'il s'était fixés. La propagande devint alors le principal instrument d'intervention sanitaire auprès de la population.

5 Comme le montre le troisième chapitre, l'un des thèmes dominants de cette propagande concernait les loisirs, que les hygiénistes cherchaient à contrôler et à rationaliser afin de rendre les travailleurs plus responsables et productifs. Désormais, sport et excursions devaient remplacer alcool et cabaret. Les Soviétiques étaient donc invités à fréquenter les clubs et les musées, mais aussi les institutions du Narkomzdrav où ils pouvaient mener une vie saine, en pratiquant des activités physiques et en s'alimentant de manière équilibrée. Toutefois, les résistances furent nombreuses et le succès limité. De plus, le nombre insuffisant d'établissements ne permettait pas d'accueillir tous les demandeurs. En 1928, Moscou ne comptait que 38 "maisons de repos » et Leningrad, 30. Seule une minorité était susceptible d'échapper au quotidien d'un appartement trop petit, surpeuplé ou insalubre.

6 La tenue du logis (ch.IV) fut une autre préoccupation majeure, car elle devait notamment prévenir la propagation des maladies. En raison de ce lien symbolique tissé entre état du domicile et état de la société, l'hygiène personnelle était érigée en devoir civique pour tout un chacun. Il reste que c'était à la femme de s'occuper du foyer : elle en était responsable et devait en assurer l'entretien, c'est-à-dire l'aérer régulièrement, le nettoyer (si possible) à grande eau, veiller à ce que le soleil y pénètre. Les enfants, pris en charge par le système éducatif soviétique qui leur inculquait ces règles, étaient censés aider leur mère. Leur rôle allait même au-delà, puisqu'ils étaient chargés de faire disparaitre au sein du foyer toute trace de misère (alcoolisme) ou de l'ordre ancien (icône).

7 L'intervention des hygiénistes dans la relation entre parents et enfants fut encore plus marquée dans le domaine de la périnatalité et de la puériculture, comme le souligne le cinquième chapitre. Dès 1918, un Département pour la protection de la mère et de l'enfant (Otdel ohrany materinstva i mladenčestva) fut créé ; il supervisait un certain nombre d'institutions: maternités, orphelinats ou cliniques d'avortement. La maternité, en devenant l'affaire de professionnels de la santé, fut placée sous le pouvoir du médecin, érigé en figure d'autorité. Les mères furent priées d'en respecter scrupuleusement les 
prescriptions jusque dans l'intimité du domicile. Ainsi, le nouveau-né devait être élevé dans un environnement sain et allaité suivant des horaires précis.

$8 \mathrm{Au}$ total, tous les domaines de la vie et des habitudes étaient redéfinis. Le corps luimême, auquel est consacré le dernier chapitre, devait être entretenu, voire remodelé. Les pratiques sportives, le brossage des dents et le bain furent vivement recommandés. Pour certains hygiénistes, le sport, dont les bénéfices étaient à la fois culturels et économiques, avait aussi la vertu d'éloigner des vices : excès de nourriture, sexe, mais surtout tabac et boisson qui détruisent le corps, l'esprit et la société. L'alcool surtout menait, selon eux, à la drogue, la délinquance ou la prostitution. Pour les individus drogués, alcooliques ou atteints de maladies vénériennes, le Narkomzdrav créa des institutions où ils pouvaient se soigner pour (re)devenir des citoyens actifs et productifs, participant à l'édification du socialisme.

Tricia Starks nous offre ainsi une passionnante histoire du discours sur le corps, élaborée par le nouvel État issu d'Octobre, ainsi que celle des techniques développées pour l'entretenir. Elle s'attache à chaque fois à contextualiser l'expérience soviétique par des mises en perspective historiques et des comparaisons avec les grands pays d'Europe et les États-Unis. À bien des égards, la trajectoire fut similaire: par exemple, la politique nataliste, partout pratiquée, engendra une médicalisation de la maternité. Mais, à travers son récit, l'auteur rend également compte d'autres phénomènes et, ce faisant, des contradictions internes au projet soviétique. La place et le rôle de la femme apparaissent ainsi bien ambigus. À l'image de la camarade émancipée et libérée du poids de sa famille, les hygiénistes opposèrent celle de la Soviétique confinée au domicile qu'elle avait la responsabilité de maintenir rangé et propre, malgré l'absence de commodités élémentaires. Par ailleurs, le souci hygiéniste d'organiser les journées des Soviétiques était porteur d'une forme d'aliénation par rapport à l'horloge et au temps : les activités étaient minutées et rationalisées, reflétant l'empreinte du taylorisme, sorti des murs de l'usine pour gagner les différents aspects de la vie, au nom d'un idéal scientiste.

L'ouvrage, convaincant, bien mené, richement illustré, suscite tout de même quelques interrogations. L'auteur évoque " hygiénistes » ou "réformateurs » sans expliciter ce qu'elle entend par là. Ce qui aurait pu être sans importance le devient dans la mesure où le lecteur ignore tout d'eux. Qui étaient-ils? Quels furent leurs parcours professionnels et individuels? Leur influence au sein du commissariat à la Santé et de l'État ? Répondre à ces questions aurait permis non seulement de donner de la chair à des théories qui paraissent comme désincarnées, mais aussi de montrer les tensions qu'accompagna la mise en concurrence de projets différents. À cet ensemble d'interrogations s'en ajoute un second qui concerne les résultats de la politique hygiéniste au sein de la population: les Soviétiques y furent-ils réceptifs? Essayèrent-ils d'appliquer les prescriptions des médecins publicisées par la propagande? L'auteur a raison de dire qu'il est ardu de dépeindre ce qu'il en fut réellement. On voudrait quand même avoir des éléments de réponse, et ce d'autant plus que certaines des mesures préconisées au cours des années 1920 sont des normes, du moins discursives, de la Russie d'aujourd'hui. 